\title{
Creencias y actitudes de los jóvenes universitarios rioplatenses hacia las variedades cultas del español
}

\author{
Sofía Gutiérrez Böhmer* \\ Facultad de Filosofia y Letras, Universidad de Buenos Aires \\ Claudia Borzi** \\ Consejo Nacional de Investigaciones Cientificas y Técnicas (CONICET) y \\ Universidad de Buenos Aires
}

\begin{abstract}
Resumen
El presente trabajo da cuenta de las actitudes lingüísticas de 89 hablantes de español rioplatense hacia las variedades del español, incluyendo la suya propia. El trabajo se inserta dentro del marco más amplio del Proyecto para el estudio de las variedades del español en el siglo XXI (PRECAVES XXI). De entre los resultados obtenidos, se destaca el hecho de que los informantes rioplatenses perciben su propia variedad como positiva, aunque no consistentemente. Asimismo, predominan las actitudes positivas hacia las otras variedades, con excepción de la variedad castellana, que recibe con frecuencia la menor valoración.
\end{abstract}

* Para correspondencia, dirigirse a: Sofía Gutiérrez Böhmer (sofia.bohmer@filo.uba.ar), Facultad de Filosofía y Letras, Universidad de Buenos Aires, Argentina.

** Para correspondencia, dirigirse a: Claudia Borzi (cborzi@filo.uba.ar), Consejo Nacional de Investigaciones Científicas y Técnicas (CONICET) y Universidad de Buenos Aires, Argentina. 
Palabras clave: creencias lingüísticas, actitudes lingüísticas, variedades del español, PRECAVES XXI, región rioplatense, sociolingüística.

\title{
Beliefs AND ATTITUdES OF YOUNG RiOPLATENSE UNIVERSITY STUDENTS TOWARDS THE EDUCATED VARIETIES OF SPANISH
}

\begin{abstract}
This work explores the linguistic attitudes of 89 speakers of Rioplatense Spanish towards both current Spanish varieties and their own. From a methodological point of view, the study is inserted within the framework of a larger project named Project for the study of beliefs and attitudes towards current Spanish varieties (PRECAVES XXI). Among the results obtained, it highlights the fact that the Rioplatense informants perceive their variety as positive but not consistently. Likewise, positive attitudes towards other varieties prevail, with the exception of Castilian variety, which regularly obtains the lowest evaluations.
\end{abstract}

Keywords: linguistic beliefs, linguistic attitudes, varieties of Spanish, PRECAVES XXI, Rioplatense area, Sociolinguistics

Recibido: 31/01/2018 Aceptado: 09/04/2018

\section{INTRODUCCIÓN}

El presente trabajo se inscribe dentro del marco del proyecto PRECAVES XXI $^{1}$ (Cestero y Paredes 2015a; 2015b; Paredes y Cestero, 2018), cuyo objetivo es avanzar en el conocimiento de las percepciones de los individuos acerca de la lengua y sus variedades, y las repercusiones que tienen o puedan tener. La base teórica y metodológica de PRECAVES XXI se explica detalladamente en el artículo primero de este monográfico (Cestero y Paredes 2018).

1 Proyecto para el estudio de las creencias y actitudes hacia las variedades del español en el siglo XXI. 
Si bien, en la zona rioplatense, el interés en la opinión de los hablantes sobre su propia lengua fue relevante para el Instituto de Filología y Literaturas Hispánicas de la Facultad de Filosofía y Letras de la Universidad de Buenos Aires durante la dirección de Amado Alonso (desde 1927 hasta 1946), estos estudios "se han generalizado en las tres últimas décadas" (Acuña y Moure 1999).

Uno de los primeros trabajos del período corresponde a Borello (1964). En su breve escrito, se dan fundamentos para una actitud autonomista por parte de muchos argentinos, sugiriendo también un rechazo hacia el español peninsular. Sin embargo, predominan los trabajos en los que se manifiesta la tensión existente entre una actitud positiva hacia la propia variedad, asociada al grado de identidad, y una actitud negativa relacionada con la subordinación a una norma peninsular. Entre estos trabajos se encuentran los de Solé (1992), Acuña y Moure (1999), Rojas Mayer (2001), López García (2013) y Llull y Pinardi (2014).

La investigación de Solé (1992) sobre las actitudes lingüísticas del hablante bonaerense culto se basó en entrevistas personales y en 350 cuestionarios. Entre otras cosas, se encontró que el 59\% de los encuestados opinaba que el español porteño no se puede considerar como "buen español" y que, para un $42 \%$ de los encuestados, España es el país en el que mejor se habla. A pesar de esto, la mitad de los encuestados no demostraba inseguridad lingüística, sino que sentía orgullo de la propia variedad y, al identificarse con ella, le atribuían valores positivos.

Acuña y Moure (1999) realizaron, para Ciudad Autónoma de Buenos Aires y Gran Buenos Aires, 600 encuestas cara a cara sobre un cuestionario semiestructurado y han encontrado, entre otros resultados, que los hablantes perciben el buen hablar como consecuencia de haber accedido a los estudios (77\%). Respecto de aquellos que "hablan mal", las respuestas son más variadas y apuntan a gente sin educación, a los jóvenes, a la mayoría de las personas y a los extranjeros (los cuatro grupos suman un $60 \%$ ). Nuevamente, la razón que se destaca a la hora de explicar el mal hablar es la falta de educación (65.2\%). Los autores concluyen que los hablantes tienden a identificar los rasgos marcados de grupo como incorrectos y que sus respuestas dan cuenta de la tensión entre lo identitario y lo general.

Rojas Mayer (2001) hace un rastreo de las actitudes lingüísticas en Argentina a lo largo del siglo XX, partiendo del conflicto lingüístico-cultural, del que participó la generación del 37, entre el español peninsular y la modalidad argentina. El siglo XX, que comienza con el español compartiendo espacios con el francés y el italiano, cambia en 1914 cuando el porcentaje de españoles duplica el de los italianos, lo cual refuerza la presencia de los primeros en la prensa. Esto vuelve a modificarse hacia 1930, época en que 
decrece el número de españoles y el hablante argentino, a juicio de la autora, acrecienta su orgullo. No obstante, se observa que, si bien la población muestra preferencia por el uso de las variedades lingüísticas regionales, los hablantes de nivel sociocultural medio y alto exteriorizan una actitud de respeto hacia la norma académica hispánica. Concluye que las actitudes manifestadas por los hablantes argentinos no han sido homogéneas en todos los tiempos y que los criterios de los ciudadanos son distintos. Aun así, se puede ver que las normas cultas nacionales han tendido a salvar algunos prejuicios intra-nacionales y a fijar su atención en la norma hispánica o panhispánica como paradigma ejemplar para las circunstancias en que lo requiera la comunicación.

López García (2013) analiza 388 encuestas cara a cara sobre un cuestionario semiestructurado para la Ciudad Autónoma de Buenos Aires y cinco municipios del conurbano bonaerense. Se parte de la hipótesis de que en Argentina la metáfora del crisol de razas canceló la respuesta expulsiva hacia la inmigración de fines del siglo XIX, pero que no ha logrado contener la emergencia de nuevas estrategias expulsivas hacia los nuevos inmigrantes. En las encuestas aparece una correlación entre la correcta expresión y el buen comportamiento, representación propia de la escuela del siglo XIX. Como en Acuña y Moure (1999), se asocia el buen hablar con la educación. Con respecto al mal hablar, el texto se enfoca en la amenaza que representan los hablantes extranjeros de países limítrofes y su contacto con otras lenguas por atentar contra la pureza y la homogeneidad, entendidas como garantías de intercomunicación. Tal situación resulta funcional al deseo de instalación de una lengua global capaz de excluir a quienes posean marcas indeseadas.

El trabajo más extenso en el tratamiento del tema les corresponde a Llull y Pinardi (2014). Las autoras analizan 400 encuestas presenciales, directas y orales, utilizando un cuestionario estándar de base semiestructurada. Algunas de las observaciones más relevantes son la existencia de un alto grado de identificación y orgullo por la propia variedad lingüística y la apreciación de la misma simultáneamente como correcta, incorrecta y desagradable. En lo que respecta a la unificación de la norma lingüística, hallan que el $66 \%$ de los encuestados (55.3\% del segmento etario más joven) elige alguna variedad como mejor. Si bien una parte de la población todavía conserva una representación de la variedad de España como lengua portadora de corrección lingüística ( $30 \%$ de los encuestados), se trata de los grupos lingüísticamente más conservadores (de menor nivel educativo y mayor edad). En una dirección diferente se ubican las respuestas que rechazan un modelo único y que son sostenidas por los segmentos de la población más jóvenes y de mayor nivel educativo (31.3\% y $24.6 \%$ respectivamente). Tales hechos pueden interpretarse como signos incipientes de cambio en las 
actitudes lingüísticas y de reemplazo de la norma peninsular. El habla de la mayoría de los países cuenta con gran aceptación y el castellano peninsular y el rioplatense, en sus variedades uruguaya y argentina, fueron los polos que concitaron mayores preferencias. En particular, Uruguay recibe los índices más altos de percepción positiva y de aceptación.

En relación con el presente trabajo, en el apartado 2 se presentará, de manera sucinta, la metodología; en el apartado 3 se expondrán los resultados, que responden a tres preguntas centrales: (1) ¿Para los sujetos estudiados, existe alguna variedad de español que pueda considerarse mejor o más prestigiosa?; (2) ¿Qué percepción tienen de su propia variedad?; y (3) ¿En qué medida identifican y valoran el resto de las variedades cultas del español? Finalmente, se extraerán algunas conclusiones.

\section{METODOLOGÍA}

Las encuestas analizadas han sido reunidas entre los años 2014 y 2017 . La muestra queda constituida por 89 encuestas que presentan la distribución expuesta en la Tabla 1.

\begin{tabular}{llcc}
\hline & Categoría & Frecuencia & Porcentaje \\
\hline Sexo & Mujeres & 70 & 78.65 \\
& Hombres & 15 & 16.85 \\
\multirow{5}{*}{ Edad } & No contesta & 4 & 4.49 \\
& Menores de 20 & 25 & 28.09 \\
\multirow{3}{*}{ Procedencia } & Entre 20 y 34 & 64 & 71.91 \\
& Buenos Aires (CABA) & 64 & 71.91 \\
& Gran Buenos Aires (GBA) & 22 & 24.72 \\
& Provincia de Buenos Aires & 2 & 2.25 \\
& Otros & 1 & 1.12 \\
\multirow{5}{*}{ Formación } & Sin formación dialectal & 44 & 49.44 \\
& Con formación dialectal & 42 & 47.19 \\
& Profesores ELE & 3 & 3.37 \\
\cline { 2 - 4 } & & &
\end{tabular}

Tabla 1. Distribución de la muestra 
Toda conclusión de significatividad se calculará con la prueba del Chi cuadrado $^{2}$, comparando el p-valor con el nivel de significación 0.05 .

\section{RESULTADOS}

\subsection{El PRESTIGIO DE LAS VARIEDADES}

Este apartado buscará dar respuesta a la pregunta ¿Para los sujetos estudiados, existe alguna variedad de español que pueda considerarse mejor o más prestigiosa? Y se considerarán sucesivamente los resultados obtenidos para cada pregunta en particular.

A la pregunta ¿Dónde cree que se habla mejor el español?, el 32.58\% de los encuestados eligió la opción "Ninguna/Todas", que es el porcentaje mayoritario si se despliegan todas las categorías contempladas en el proyecto ${ }^{3}$. Por otra parte, se encuentran quienes dejan la pregunta sin respuesta, cifra también significativa, que se puede tratar de justificar pensando en que las preguntas parciales dan por supuesta la verdad del contenido y en que la formulación de la pregunta de la encuesta puede haber generado resistencia a responder por parte del encuestado ${ }^{4}$. La pregunta está dando por sentado que hay un lugar del mundo hispanohablante en el que se habla mejor. Así pues, si agregamos a quienes respondieron "Ninguna/Todas" (que es una forma de no responder) el $13.48 \%$ de personas que no responden, el porcentaje de personas que explícita o implícitamente no participan de la atribución de una posición de jerarquía a ninguna de las variedades asciende al $46.06 \%$. Estos resultados nos permiten sostener que existe una marcada preferencia

2 Esta prueba comprueba si la distribución de dos variables es independiente o interdependiente; es decir si su asociación es o no es azarosa.

3 Estas son: en todas las regiones se habla bien, en la zona castellana, en la andaluza, en la canaria, en la española en general, en la zona andina, en la caribeña, en la mexicana, en la chilena, en la rioplatense, en la hispanoamericana en general y otros.

4 Al respecto, Gili Gaya sostiene: "En las interrogaciones parciales la duda no recae sobre el predicado mismo de la oración, sino sobre el sujeto [...] o cualquiera de los demás elementos de la oración." (1955: 45).

5 Es notable la consistencia de nuestros resultados con los de Llull y Pinardi (2014). Para el mismo segmento etario, las autoras obtienen que el $13.4 \%$ se resiste a responder mediante la elección de la opción "No sabe". 
por una norma pluricéntrica en los segmentos de menor edad y mayor nivel educativo, resultado compartido por Llull y Pinardi (2014: 36).

Un 52.81\%, no obstante, considera alguna variedad como mejor. De estos, el 52.08\% (28.09\% del total de encuestados) elige su propia variedad. El 18.75\% (10.12\% del total) refiere al español peninsular en alguna de sus variedades (castellana, andaluza o española en general). El número que obtuvimos es inferior al obtenido por Llull y Pinardi, cuya investigación, para el mismo segmento etario, arrojó una preferencia por el español peninsular del 23.1\% de los casos y, para el mismo nivel educativo, del 23\% (2014: 37).

La tabla 2 contiene todas las respuestas dadas en orden descendente.

\begin{tabular}{|c|c|c|c|}
\hline Variedad & & Frecuencia & Porcentaje \\
\hline Ninguna & & 29 & 32.58 \\
\hline Rioplatense & & 25 & 28.09 \\
\hline $\mathrm{N} / \mathrm{C}$ & & 12 & 13.48 \\
\hline España & & 7 & 7.87 \\
\hline Andina & & 7 & 7.87 \\
\hline Castellana & & 2 & 2.25 \\
\hline Caribeña & & 2 & 2.25 \\
\hline Hispanoamérica & & 2 & 2.25 \\
\hline Otro & & 2 & 2.25 \\
\hline Mexicana & & 1 & 1.12 \\
\hline Canaria & & 0 & 0.00 \\
\hline Andaluza & & 0 & 0.00 \\
\hline Chilena & & 0 & 0.00 \\
\hline & Total: & 89 & 100.00 \\
\hline
\end{tabular}

Tabla 2. Regiones en las que se habla "mejor"

A continuación, se analizarán algunas variables sociales en función de su significatividad a la hora de atribuir jerarquía o considerar la igualdad ${ }^{6}$ entre las diferentes variedades.

\footnotetext{
6 Para calcular el p-valor se descartan las respuestas "Otros" y "No contesta". También, se prescinde de las variables estadísticamente poco significativas que concentran todos los datos en una de las opciones, dejando la casilla opuesta con valor 0 .
} 


\subsubsection{Variables no significativas}

\subsubsection{Procedencia}

Dados los datos relevados a la fecha, que se vuelcan en la tabla 3 , la variable "Procedencia" parece no afectar la atribución de jerarquía/igualdad a las diferentes variedades del español ( $\mathrm{p}$-valor $=0.5716$ ). Se ve en la horizontal que, de entre los encuestados procedentes de CABA, el $62.26 \%$ prefiere alguna de las variedades, mientras que el $37.74 \%$ las considera iguales. $\mathrm{Al}$ mismo tiempo, el 55\% de los encuestados procedentes del GBA considera que existe una jerarquía, mientras que el $45 \%$ opta por la igualdad ${ }^{7}$. Con todo, se percibe una cierta tendencia de las personas provenientes de CABA a preferir alguna de las variedades como mejor.

\begin{tabular}{|l|cc|cc|cc|}
\cline { 2 - 7 } \multicolumn{1}{c|}{} & \multicolumn{2}{c|}{ Jerarquía } & \multicolumn{2}{c|}{ Igualdad } & \multicolumn{2}{c|}{ Total } \\
\cline { 2 - 7 } \multicolumn{1}{c|}{} & $\mathbf{N}$ & $\%$ & $\mathbf{N}$ & $\%$ & $\mathbf{N}$ & $\%$ \\
\hline CABA & 33 & 62.26 & 20 & 37.74 & 53 & 100.0 \\
\hline GBA & 11 & 55.00 & 9 & 45.00 & 20 & 100.0 \\
\hline Total & 44 & 61.11 & 29 & 38.99 & 73 & 100.0 \\
\hline
\end{tabular}

Tabla 3. Jerarquía o igualdad de las variedades, por procedencia

\subsubsection{Sexo}

La variable "Sexo" tampoco determina una distribución relevante (p-valor= 0.3906). Sí se observa, en la lectura horizontal, una ligera predisposición por parte del sexo masculino a favor de la jerarquía (72.72\%), pero habrá que cotejar en el futuro con una muestra más balanceada ${ }^{8}$.

\begin{tabular}{|c|cc|cc|cc|}
\cline { 2 - 7 } \multicolumn{1}{c|}{} & \multicolumn{2}{|c|}{ Jerarquía } & \multicolumn{2}{c|}{ Igualdad } & \multicolumn{2}{c|}{ Total } \\
\cline { 2 - 7 } \multicolumn{1}{c|}{} & $\mathbf{N}$ & $\%$ & N & $\%$ & N & $\%$ \\
\hline Masculino & 8 & 72.72 & 3 & 27.28 & 11 & 100.0 \\
\hline
\end{tabular}

7 Para la variable "Procedencia" se han descartado 16 casos correspondientes a "Otros" (1), "No contesta" (12), "Provincia de Buenos Aires" (2) y "Otras provincias" (1).

8 Para la variable "Sexo" se han eliminado 17 casos correspondientes a "Otros" (1), "No contesta" (12) y "No especifica sexo" (4). 


\begin{tabular}{|l|rr|rr|rr|}
\hline Femenino & 36 & 59.01 & 25 & 40.99 & 61 & 100.0 \\
\hline Total & 44 & 61.11 & 28 & 38.99 & 72 & 100.0 \\
\hline
\end{tabular}

Tabla 4. Jerarquía o igualdad de las variedades, por sexo

\subsubsection{Variables significativas}

\subsubsection{Edad}

Como se muestra en la primera fila de la tabla 5, el grupo de menores de 20 años prefiere, en el $85.71 \%$, la jerarquía; en la segunda fila, el rango etario más numeroso (aquellos entre 20 y 34 años) exhibe resultados en el nivel del azar (52.72\% a favor de la jerarquía, $47.28 \%$ a favor de la igualdad). El p-valor, para esta muestra, es $0.0081^{9}$.

\begin{tabular}{|l|cc|cc|cc|}
\cline { 2 - 7 } \multicolumn{1}{c|}{} & \multicolumn{2}{c|}{ Jerarquía } & \multicolumn{2}{c|}{ Igualdad } & \multicolumn{2}{c|}{ Total } \\
\cline { 2 - 7 } \multicolumn{1}{c|}{} & $\mathbf{N}$ & $\%$ & $\mathbf{N}$ & $\%$ & $\mathbf{N}$ & $\%$ \\
\hline $\mathbf{- 2 0}$ años & 18 & 85.71 & 3 & 14.29 & 21 & 100.0 \\
\hline $\mathbf{2 0 - 3 4}$ años & 29 & 52.72 & 26 & 47.28 & 55 & 100.0 \\
\hline Total & 47 & 61.84 & 28 & 38.26 & 76 & 100.0 \\
\hline
\end{tabular}

Tabla 5. Jerarquía o igualdad de las variedades, por edad

\subsubsection{Formación}

"Formación" también se manifiesta como significativa (p-valor=0.0013). Los encuestados sin formación en variedades (tabla 6, fila primera) han respondido a favor de la existencia de una jerarquía en el $80 \%$, mientras que los informantes con dicha formación muestran resultados al nivel del azar, con una leve inclinación hacia la igualdad de las variedades $(44.11 \%$ jerarquía y $55.89 \%$ igualdad) ${ }^{10}$.

9 Para la variable "Edad" hemos prescindido de 13 casos correspondientes a "Otros" (1) y "No contesta" (12).

10 Para la variable "Formación" hemos descartado 15 casos correspondientes a "Otros" (1), "No contesta" (12) y "Profesores de Español como Lengua Extranjera" (2). 


\begin{tabular}{|l|cc|cc|cc|}
\cline { 2 - 8 } \multicolumn{1}{c|}{} & \multicolumn{2}{c|}{ Jerarquía } & \multicolumn{2}{c|}{ Igualdad } & \multicolumn{2}{c|}{ Total } \\
\cline { 2 - 8 } \multicolumn{1}{c|}{} & $\mathbf{N}$ & $\%$ & $\mathbf{N}$ & $\%$ & $\mathbf{N}$ & $\%$ \\
\hline Sin formación & 32 & 80.00 & 8 & 20.00 & 40 & 100.0 \\
\hline Con formación & 15 & 44.11 & 19 & 55.89 & 34 & 100.0 \\
\hline Total & 47 & 63.51 & 27 & 36.49 & 74 & 100.0 \\
\hline
\end{tabular}

Tabla 6. Jerarquía o igualdad de las variedades, por formación

Tales resultados pueden interpretarse como signos de que la formación puede modificar actitudes lingüísticas en detrimento de una norma única y a favor de una norma pluricéntrica. A pesar de esto, y dado que la población estudiada corresponde a jóvenes estudiantes universitarios, es probable que exista una correspondencia entre mayor edad y mayor nivel de formación, con lo que se vuelve difícil independizar ambas variables.

\subsection{Percepción de La VARIEDAd PRopia}

Este apartado dará respuesta a la pregunta sobre qué percepción tienen los sujetos estudiados sobre su propia variedad.

\subsubsection{Valoración directa de la variedad rioplatense}

Con el primer bloque de preguntas, se pide al informante que valore cada variedad a través de una escala de intensidad de 6 grados, formada por adjetivos opuestos. Véase el gráfico 1.

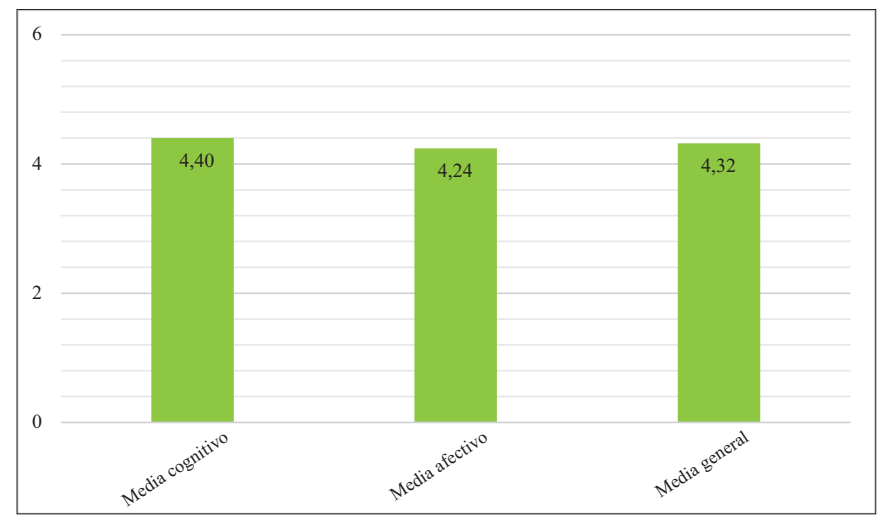

Gráfico 1. Promedio aspectos cognitivos, afectivos y general 
Como se puede observar, la valoración promedio asignada a la variedad rioplatense se encuentra en el polo positivo (4.32). El valor medio específico para los aspectos cognitivos está apenas por encima del componente afectivo (4.40 y 4.24 respectivamente).

Vale destacar que la variedad propia es la que recibe la mayor valoración en cuanto a los aspectos cognitivos, pero no sucede lo mismo con los aspectos afectivos, aspectos en los que descuella la variedad caribeña. A continuación, se analizarán los rasgos cognitivos y afectivos de manera discriminada.

\subsubsection{Valoración directa cognitiva}

En el caso de los aspectos cognitivos, el extremo mejor valorado se encuentra cómodamente en el polo positivo; urbano promedia 5.58, seguido por claro (5.10). El extremo inferior se ubica a más de dos puntos por debajo del valor máximo; el rasgo menos valorado es variado (3.47), apenas superado por suave (3.73). Por último, rápido ha obtenido un resultado intermedio (4.06).

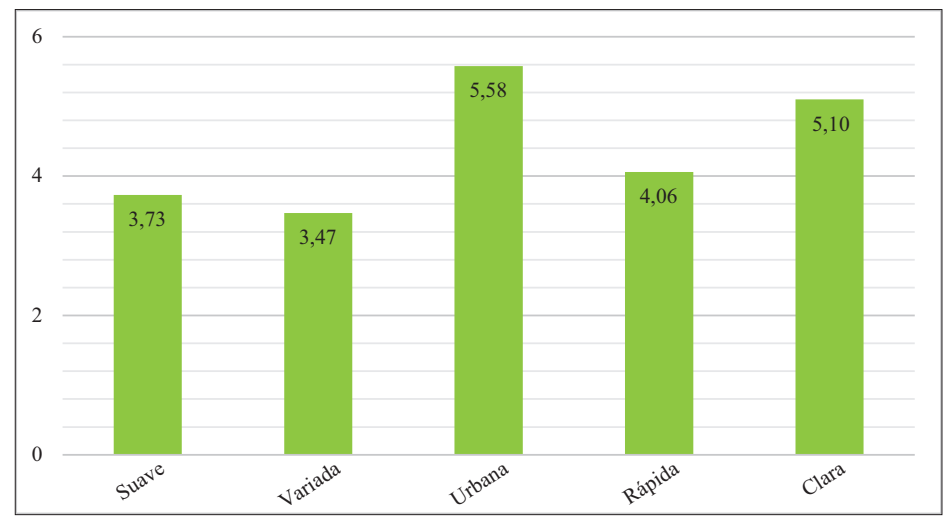

Gráfico 2. Promedio rasgos cognitivos

Es interesante notar que los dos aspectos cognitivos más salientes (urbano y claro) también son los aspectos en los que la región rioplatense obtiene la mayor valoración, si se la compara con la que han recibido otras zonas. 


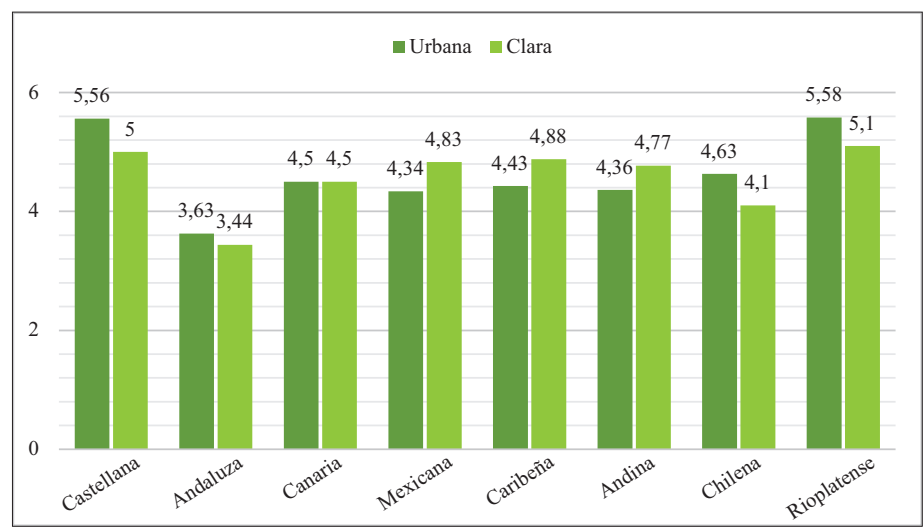

Gráfico 3. Promedios rasgos urbano y claro

Siguiendo a Rizo, una explicación posible es que el entorno urbano no debe ser abordado teóricamente como una mera dimensión física, sino que es fundamental incorporar la experiencia de quienes habitan en ella. Para ello, la autora desarrolla la idea de "identidad de lugar" y explica que "puede ser vista como parte de la identidad personal. [...] El espacio, por tanto, se organiza de forma simbólica [...]" (2006: 9).

Así pues, el concepto de urbanidad es altamente simbólico y está asociado a la identidad, razón que puede explicar la prominencia de este aspecto por encima de los otros. Por otro lado, el hecho de que la variedad castellana sea la segunda mejor valorada revela representaciones de lo urbano, lo avanzado, lo rico, a las que se hará referencia en el apartado que examina la valoración a través de la región.

Algo similar sucede con la noción de claridad, que en Llull y Pinardi (2014: 32) aparece como un atributo cargado de complejidad, pues surge (entre el $21.4 \%$ de los encuestados) como un determinante del "hablar bien". El mismo rasgo emerge como relevante también en el trabajo de Acuña y Moure (1999), quienes obtienen resultados similares (14.3\% de los hablantes lo asocia al "bien hablar").

En cierta forma, podría parecer contradictorio que sea justamente la variedad castellana la que más se acerca a la rioplatense con respecto al rasgo claridad, mientras que, por el otro lado, la misma variedad no se destaca entre quienes consideran que en algunas regiones se habla mejor que en otras (como se observa en la tabla 2). Aún más, las variedades peninsulares reciben frecuentemente la valoración más baja a lo largo del estudio, algo a lo que se hará referencia en el apartado 3.3. Sin embargo, esto no hace 
más que dar cuenta de la relación tensa entre la norma peninsular y la local, referida en la introducción.

En el extremo inferior de los aspectos cognitivos, se halla variado, lo cual es coherente con el hecho de que la acepción más corriente de variado o diverso refiera a "las personas que no son como 'nosotros', $[\ldots]$ las que tienen otras costumbres o tradiciones, [...] las que viven en otros países" (Ramos Calderón 2012: 77).

\subsubsection{Valoración directa afectiva}

Los aspectos afectivos, por otro lado, se comportan de manera un poco más uniforme. El rasgo más valorado es cercano (5.10), seguido de sencillo (4.72); en el otro extremo, por su parte, se encuentra divertido (3.40), superado por blando (3.94). Los valores intermedios los han obtenido agradable y bonito (4.13 ambos).

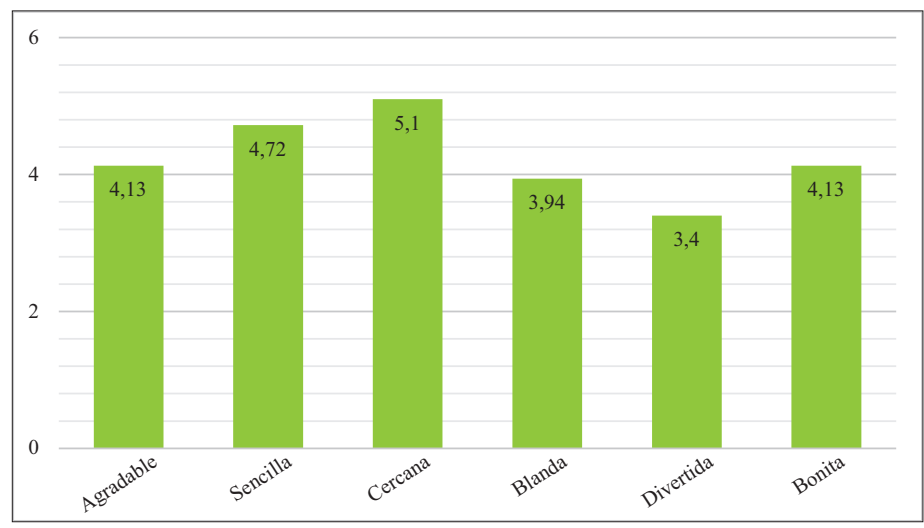

Gráfico 4. Promedios rasgos afectivos

La cualidad más prominente, cercano, es la única dentro de la valoración directa cuyo promedio supera el valor 5 . El resultado es consistente con el alto grado de identificación de y con la variedad propia, al que se referirá en los apartados 3.2.3 y 3.3.1. Es esperable que una voz, correctamente identificada y caracterizada como igual a la variedad propia, sea percibida como muy cercana. A diferencia de lo que sucede con urbano y claro, para cercano, la variedad castellana se encuentra en las antípodas (recibe un valor promedio de 2). 


\subsubsection{Aspectos valorados de la pronunciación}

Las preguntas 2 y 3 de la encuesta, últimas en el bloque de preguntas directas sobre la variedad, solicitan al informante que mencione los aspectos de la pronunciación que le hayan gustado especialmente y los que le hayan disgustado. En consonancia con el modo en que se formula la pregunta, los aspectos más mencionados son los fónicos (151 menciones); en segundo lugar, se posicionan las respuestas contenidas en otros (47 menciones) ${ }^{11}$; finalmente, aparecen los rasgos pragmáticos (14 menciones). En solo una ocasión se refiere a aspectos léxicos y en ningún caso, a aspectos gramaticales.

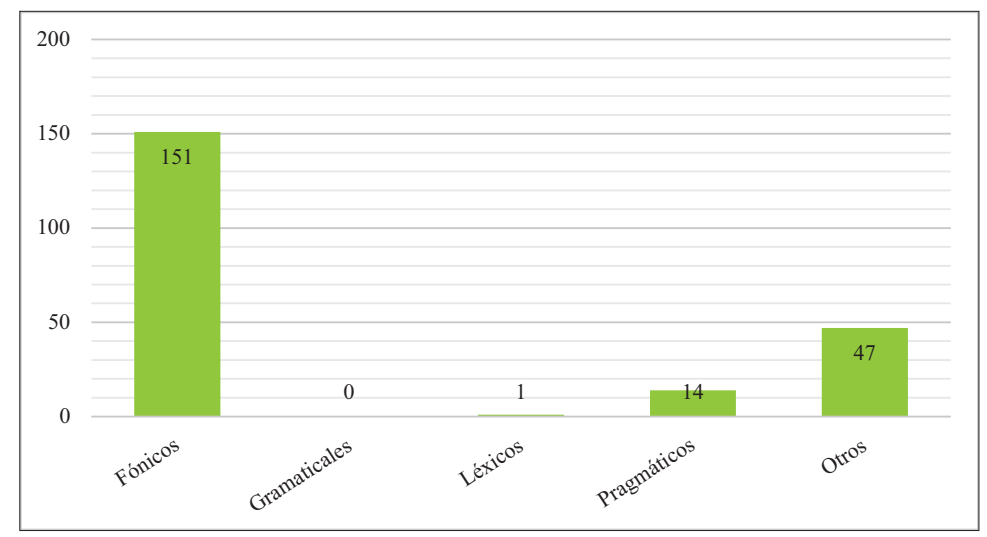

Gráfico 5. Aspectos lingüísticos valorados

El aspecto fónico positivo más valorado de la variedad rioplantese, con gran diferencia, es la claridad (39 menciones), seguida por la palatal rehilada (13 menciones). Para las opciones no lingüísticas, se destacan la cercanía y familiaridad (19 menciones).

Los aspectos fónicos menos valorados son la rapidez ( 13 menciones) y la monotonía (10 menciones). Se mencionan también rasgos que pueden estar más asociados a trastornos del habla, como lo son el sigmatismo (referido como ceceo) y la nasalidad (10 menciones entre ambos $)^{12}$. Los aspectos pragmático-discursivos en los que más se insiste son el número de pausas

1 Se incluyen respuestas tales como sencilla, interesante, alegre, bonita, dulce, etc.

12 La nasalidad también puede ser entendida como un rasgo sociolectal. En su artículo La amenaza democrática, verbigracia, el escritor e historiador Ernesto Semán se ha referido a la pronunciación de Mauricio Macri, actual presidente, como un "gangoseo de clase" (2011). 
y alargamientos (8 menciones). De entre los aspectos no lingüísticos, se destaca el aburrimiento y el desgano (7 menciones).

\subsubsection{Las voces evaluadas}

La recogida de grabaciones para el proyecto ha contemplado la incorporación de voces tanto de hombres como de mujeres. Aunque la diferencia entre los valores obtenidos para la voz femenina y la masculina no es considerable, se observa que la voz femenina recibe valores ligeramente menores a la masculina en los aspectos cognitivos y mayores en los afectivos, como se muestra en el gráfico 6 .

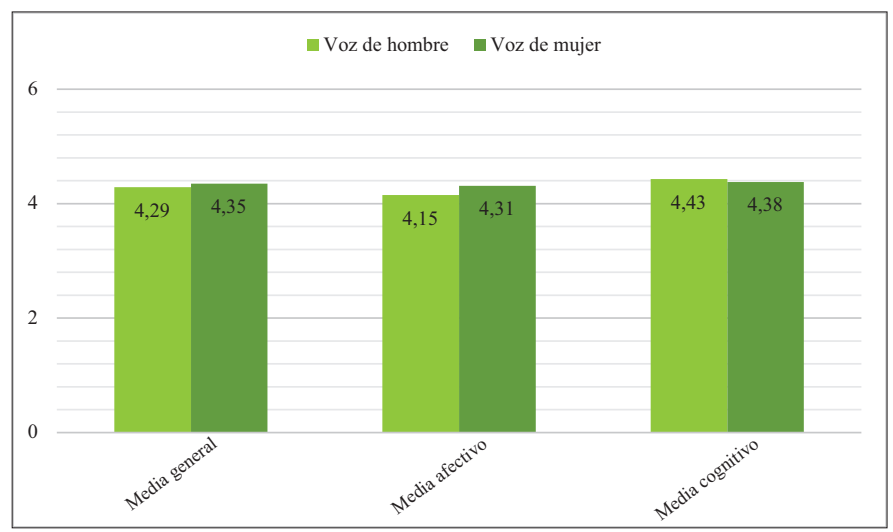

Gráfico 6. Promedios cognitivo, afectivo y general, por voz evaluada (de hombre y de mujer)

3.2.1.5. Valoración directa de la variedad rioplatense por sexo, edad, procedencia y formación de los encuestados

Al evaluar el promedio de la valoración directa en función del sexo, la edad, la procedencia y la formación de los encuestados, vemos que, a pesar de la reducida diferencia entre los valores, existe cierta consistencia en los resultados ${ }^{13}$.

En el gráfico 7, se puede ver que las mujeres tienden a valorar la propia variedad de manera más positiva que los hombres.

13 Se prescinde aquí también de las variables estadísticamente poco significativas (ver notas 6-10). 


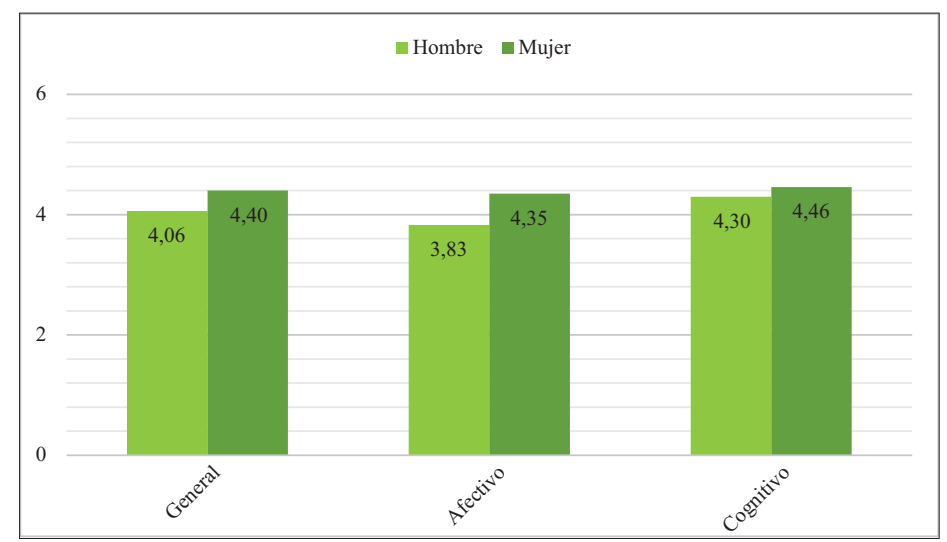

Gráfico 7. Promedios valoración directa, por sexo de los informantes

Un comportamiento similar se exhibe en el gráfico 8 y gráfico 9 , que indican la diferencia en la valoración con relación a la edad y a la formación de los informantes; los menos de 20 años hacen una mejor valoración de la propia variedad que las personas de entre 20 y 34 años (gráfico 8), como así también lo hacen los informantes sin formación en variedades en comparación con los que presentan dicha formación (gráfico 9).

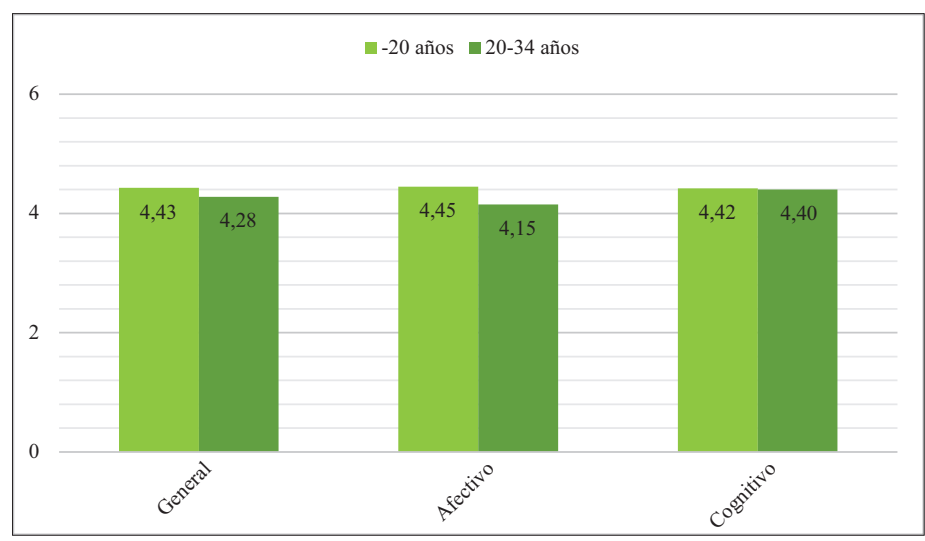

Gráfico 8. Promedios valoración directa, por edad de los informantes 


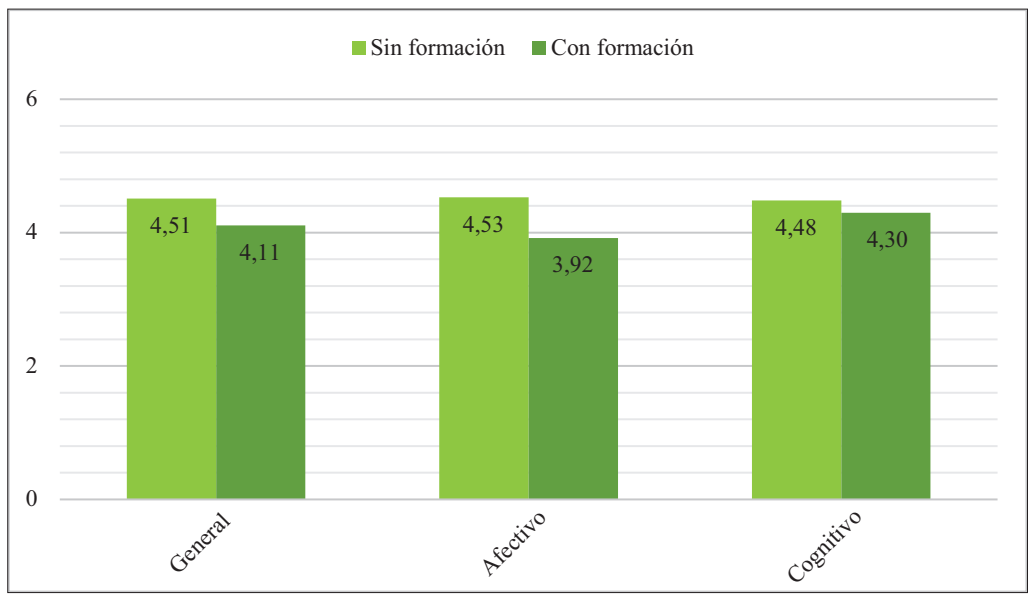

Gráfico 9. Promedios valoración directa, por formación de los informantes

Las variantes para "Procedencia", por último, manifiestan una diferencia ínfima entre ellas. Aun así, las personas procedentes de GBA han asignado una valoración levemente superior que las personas procedentes de CABA.

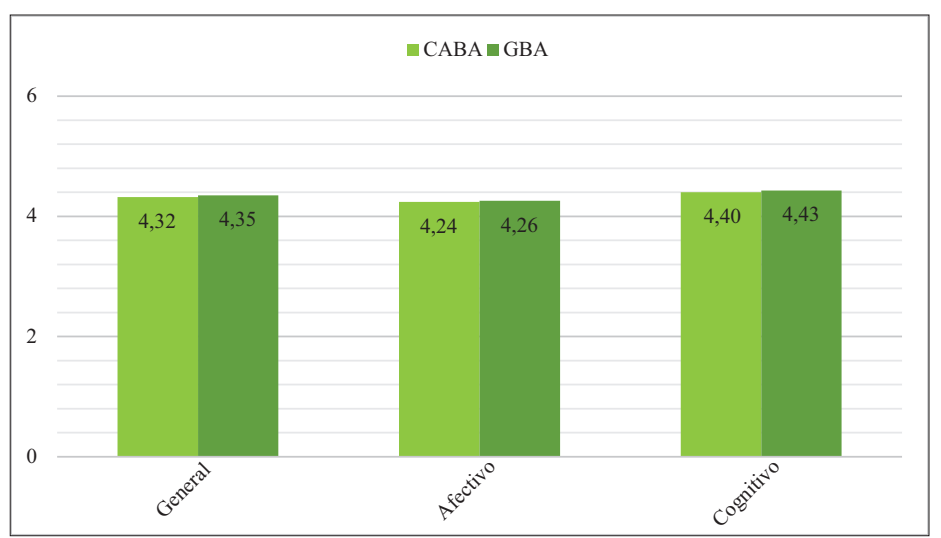

Gráfico 10. Promedios valoración directa, por procedencia de los informantes

\subsubsection{Valoración indirecta de la variedad rioplatense}

En este bloque de preguntas se pide a los informantes que emitan su opinión sobre la persona que habla y la región y cultura de la que proviene. El resultado promedio de todos los aspectos evaluados para la valoración 
indirecta indica que la propia variedad es la más favorecida por los encuestados (4.74). Se analizarán, en lo sucesivo, los rasgos discriminados correspondientes a persona, región y cultura.

\subsubsection{A través de la persona}

Como se puede observar en el gráfico 11, todos los aspectos considerados se sitúan manifiestamente por encima del valor neutro, esto es, se los evalúa de manera muy positiva.

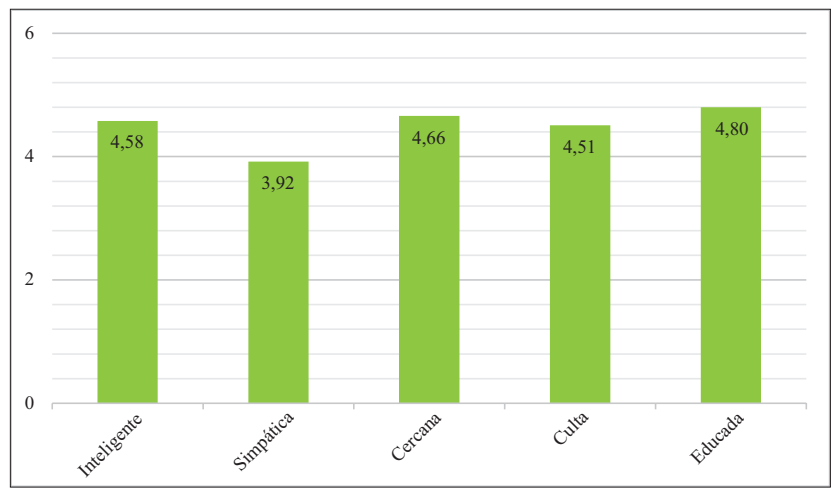

Gráfico 11. Valoración a través de la persona

De entre los aspectos más valorados, cercano es el único que también se posiciona por sobre el resto de las variedades, en línea con el comportamiento del mismo aspecto en la valoración afectiva. No será una sorpresa, pues, que el fenómeno se advierta nuevamente en el análisis de la región y de la cultura.

Parece haber un paralelo entre los resultados conseguidos aquí por simpático (3.92) y el rasgo afectivo divertido (3.40): si bien ambos valores se ubican en la franja positiva, son los menos valorados en sus respectivas categorías (valoración por persona y valoración afectiva). Algo diferente sucede para la valoración a través de la región. Se hará referencia a ello en el siguiente apartado.

Las preguntas 5 a 10 del cuestionario interrogan de manera abierta sobre la opinión que tiene el encuestado sobre la persona que habla. De entre los rasgos positivos, los informantes encuentran que las personas de la región rioplatense son agradables, amables, amigables y simpáticas (15 respuestas tomados en su conjunto). En el extremo contrario, 16 encuestados consideran a las personas de la región arrogantes, pedantes, engreídas y soberbias. 


\subsubsection{A través de la región}

Como se pudo advertir en la valoración a través de la persona, también para la región todas las características reciben una valoración positiva, con la excepción de que, en este caso, la valoración es más dispar; la menor valoración la recibe avanzado (3.90) y la mayor, familiar (5.58). Los valores intermedios les corresponden a divertido y bonito (4.64 y 5.26, respectivamente).

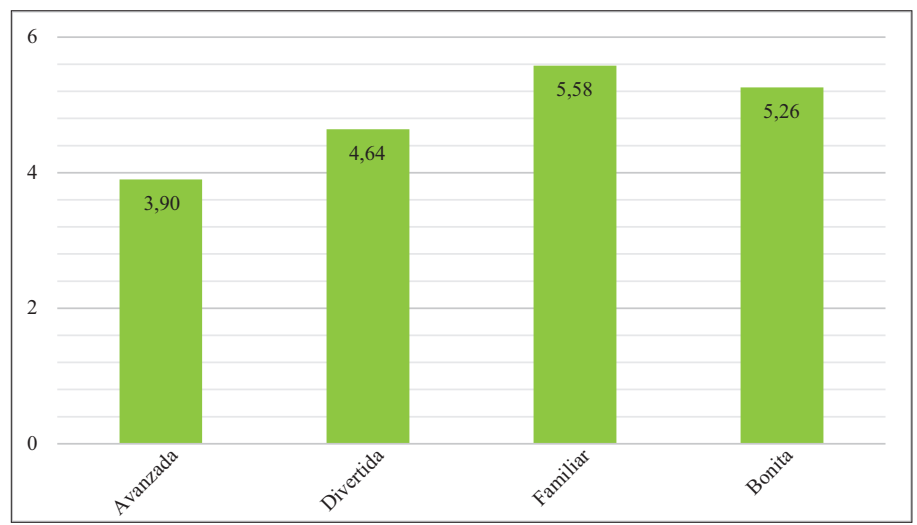

Gráfico 12. Valoración a través de la región

En la valoración a través de la región, divertido obtiene mejores resultados que las cualidades simpático y divertido mencionadas en los apartados 3.2.1.2. y 3.2.2.1. La diferencia es, empero, esperable, pues existe una contigüidad mayor entre el habla y el hablante, por un lado, que entre ambos y la región.

El atributo menos valorado, avanzado, recibe una menor valoración también para las otras variedades analizadas. La única variedad que descuella en este aspecto es la castellana. Vale destacarlo, ya que son índices de la vigencia de la idea local de que una cultura urbana, culta y civilizada es una cultura europea, idea que se mantiene desde los años en que la "generación del 37" la adoptó en su "proceso de civilización" (Marre 2003: 27). Esto explica también el alto índice obtenido por la variedad castellana para el atributo urbano en el análisis de la valoración directa cognitiva y para el rasgo rico en el análisis a través de la cultura (apartado próximo).

El atributo más valorado, familiar, se acerca semánticamente a cercano $\mathrm{y}$, consecuentemente, se comporta de manera similar al mismo, como ya se adelantó en apartados previos. 


\subsubsection{A través de la cultura}

En último lugar, se presentan los resultados de los valores promedio de la percepción indirecta a través de la cultura: la menor estimación se le atribuye a innovador (3.99) y la mayor a cercano (5.67), mientras que rico e interesante obtuvieron 4.64 y 5.24, respectivamente. Como se puede observar, la percepción de los hablantes ante la propia cultura es muy positiva.

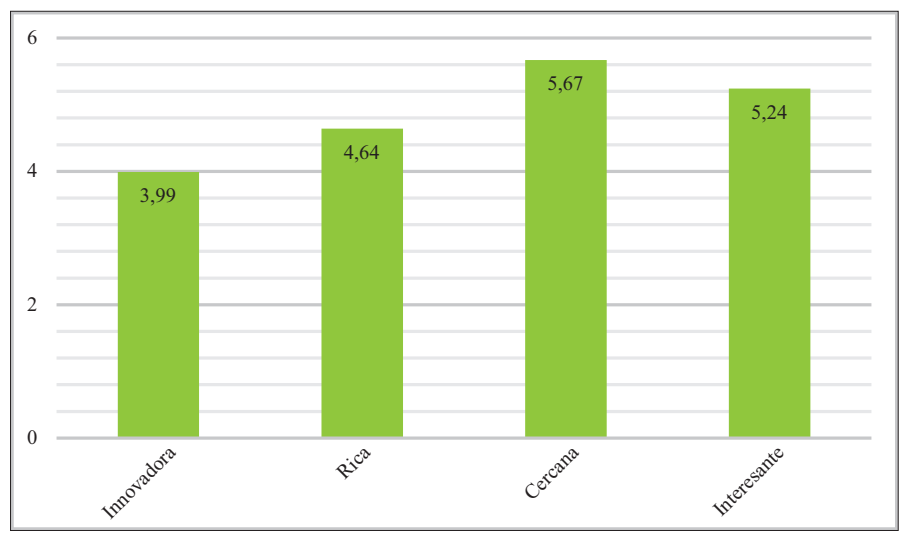

Gráfico 13. Valoración a través de la cultura

En cuanto a la cualidad innovador, la menos estimada, vale aclarar que también recibe una menor valoración en todas las variedades analizadas ${ }^{14}$. El fenómeno se puede explicar por medio de la estrecha relación que existe entre cultura y tradición ${ }^{15}$, por un lado, y el hecho de que el concepto de innovación esté tan ligado al mundo empresarial, por el otro.

Cercano es, nuevamente, el rasgo mejor estimado (tanto entre los otros rasgos aquí analizados como entre los resultados de las otras regiones); rico, el segundo menor estimado, obtiene la mayor valoración para la variedad castellana, como se mencionó en el apartado precedente.

14 El promedio general obtenido por cada rasgo es: innovador (3.23), rico (4.37), cercano (4.04) e interesante (4.95).

15 Como afirma Arévalo, "la identidad está en relación dialéctica con la tradición, es decir con la cultura y el patrimonio" (2004: 925). 
3.2.2.4. Valoración indirecta de la variedad rioplatense por sexo, edad, procedencia y formación de los encuestados

Cuando se examina el promedio de la valoración indirecta con respecto al sexo, la edad, la procedencia y la formación de los encuestados, los datos revelan, como en el inciso 3.2.1.5, escasa diferencia entre los valores y cierta consistencia en los resultados ${ }^{16}$.

Similar a lo que ocurre con la valoración directa, el gráfico 14 muestra que las mujeres valoran de manera más positiva que los hombres.

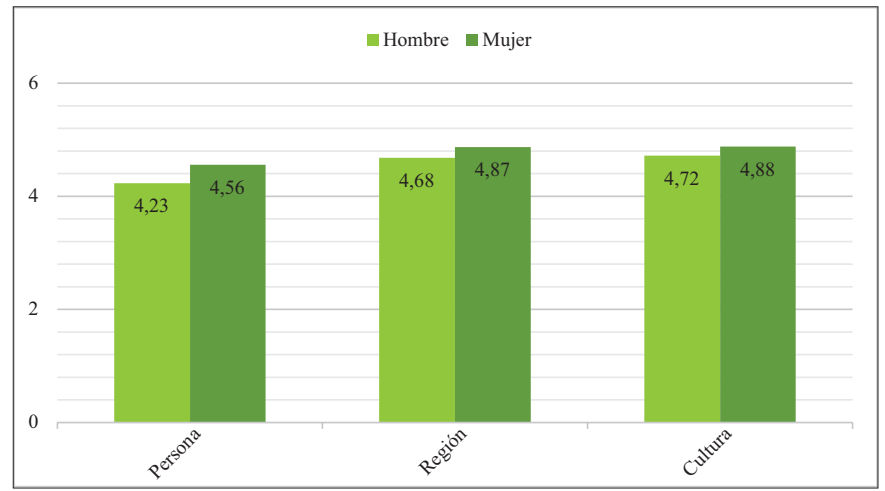

Gráfico 14. Promedios valoración indirecta, por sexo de los informantes

Por el contrario, los informantes más jóvenes, que tendían a evaluar de manera directa mejor que los hablantes entre 20 y 34 años, para la valoración indirecta solo mantienen la mencionada tendencia a la hora de valorar a la persona. En lo tocante a la región y a la cultura, asignan menor valor que el grupo de 20-34 años (gráfico 15).

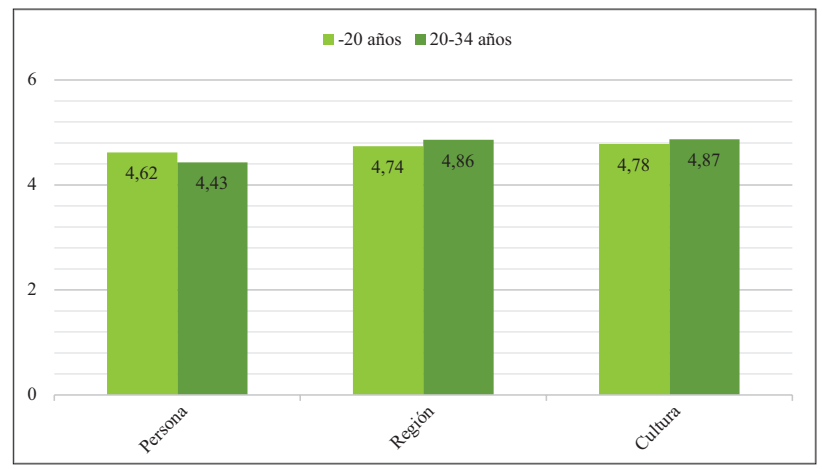

Gráfico 15. Promedios valoración indirecta, por edad de los informantes

16 Se han descartado nuevamente las variables estadísticamente poco significativas (ver notas 6-10). 
Las variantes para "Procedencia", que manifestaban una diferencia ínfima en la valoración directa (gráfico 10), en la valoración indirecta exponen valores levemente más alejados (gráfico 16). Los datos muestran que los hablantes procedentes de GBA asignan valores menores que los hablantes procedentes de CABA.

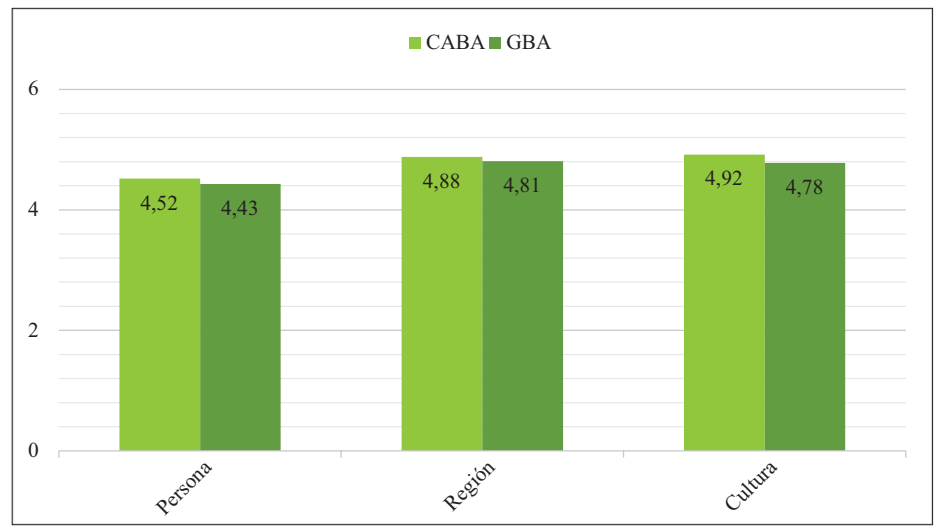

Gráfico 16. Promedios valoración indirecta, por procedencia de los informantes

En último lugar, el parámetro "Formación" parece ser relevante solo para la valoración de la persona en la grabación, a la que los informantes sin formación en variedades parecen valorar de manera más positiva que aquellos con dicha formación, como sucede en la valoración directa. En el caso de la valoración de la región y de la cultura, la diferencia es nula o muy leve.

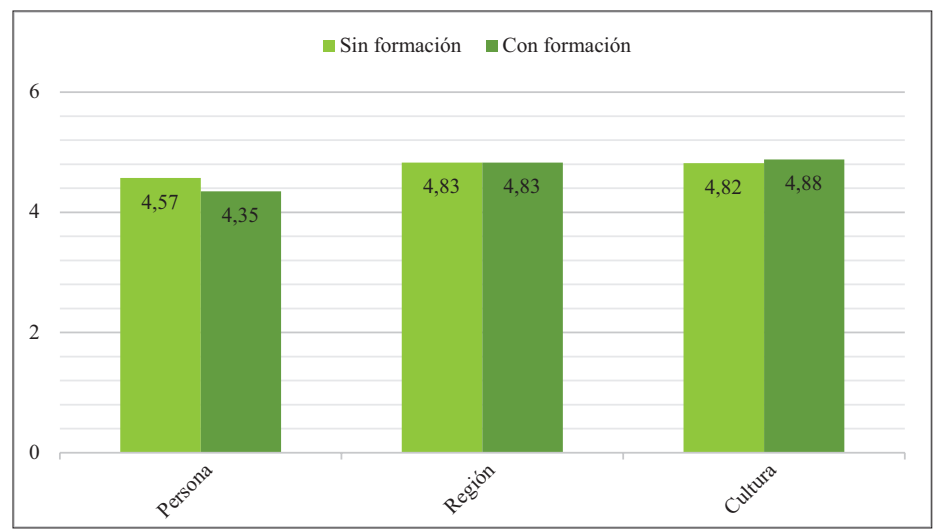

Gráfico 17. Promedios valoración indirecta, por formación de los informantes 


\subsubsection{Grado de identificación con la variedad propia}

La pregunta 4 del cuestionario solicita al informante que valore la proximidad entre su propia pronunciación y la de la persona que ha hablado. En este caso, el $94.25 \%$ considera que la voz evaluada es idéntica o similar $(3.4 \%$ ligeramente igual, $29.9 \%$ bastante igual y $60.9 \%$ totalmente idéntica). Solo el $5.17 \%$ la considera no idéntica $(2.3 \%$ totalmente diferente, $1.15 \%$ bastante diferente y $1.72 \%$ ligeramente diferente). El $0.6 \%$ no contesta.

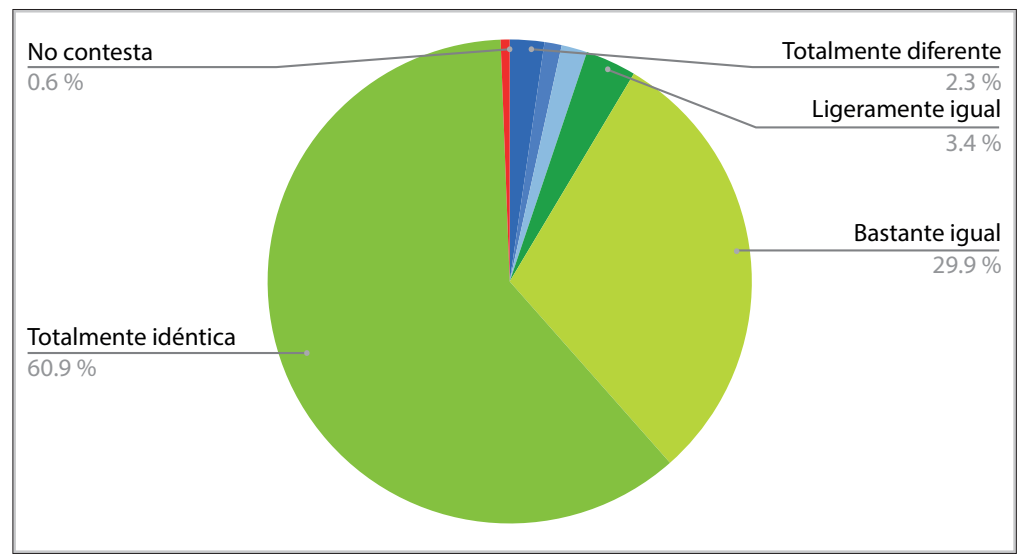

Gráfico 18. Promedio identificación con la variedad rioplatense

\subsection{IDENTIFICACIÓN Y VALORACIÓN DEL RESTO DE LAS VARIEDADES}

En este apartado se dará respuesta a la pregunta ¿En qué medida los sujetos estudiados identifican y valoran el resto de variedades cultas del español? ${ }^{17}$

17 Para el análisis del resto de las variedades, no se estimarán como relevantes los resultados obtenidos para la variedad canaria, dado que la muestra no es estadísticamente significativa: solo dos encuestados identifican correctamente dicha variedad. Se menciona aquí que la estimación por parte de estos dos encuestados es muy positiva: supera a las otras variedades en la valoración directa de aspectos afectivos (4.33), así como también en aspectos cognitivos (4.50). A su vez, sobresale por encima del resto al momento de evaluar a través de la persona (5.00) y de la región (5.13). Contrariamente, recibe los valores más bajos cuando es evaluada a través de la cultura. 


\subsubsection{Identificación}

La variedad que mejor reconocen los encuestados es la rioplatense, que alcanza casi el 100\% (97.75\%). Los resultados son, de alguna manera, afines al grado con que los hablantes se identifican con las grabaciones, referido en el apartado 3.2.3.

También alcanza una cota alta de identificación correcta la variedad chilena $(59.55 \%)$ y la mexicana $(53.37 \%)$. El resto se sitúa por debajo del $50 \%$ de aciertos: la caribeña $(47.75 \%)$, la variedad andina $(44.94 \%)$ y las tres variedades europeas, a saber, la variedad andaluza (8.99\%), la variedad castellana $(5.62 \%)$ y la variedad canaria $(1.12 \%)$.

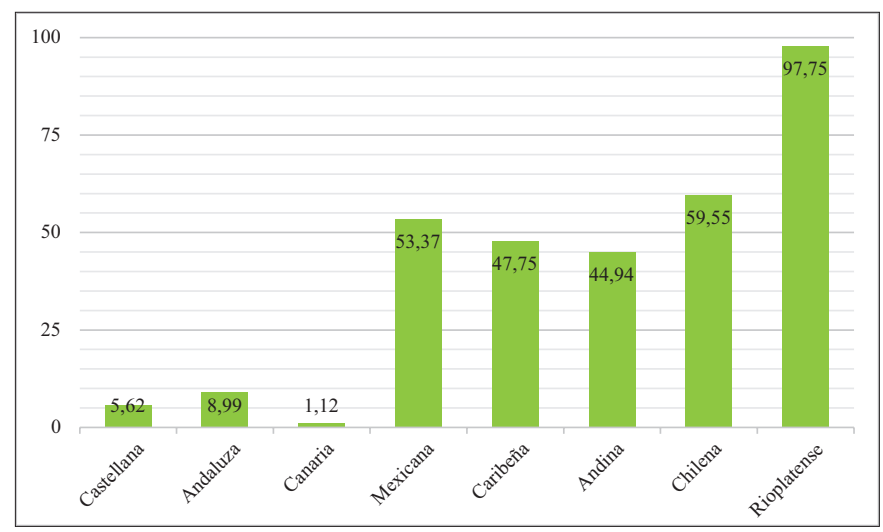

Gráfico 19. Identificación exacta de las variedades

Si consideramos los errores, la escala se repite, inversamente proporcional, para casi todas las variedades. No obstante, como se puede observar en el gráfico 20, la proporción no se mantiene en las variedades peninsulares, cuyos valores se esperarían cercanos a la variedad canaria. 


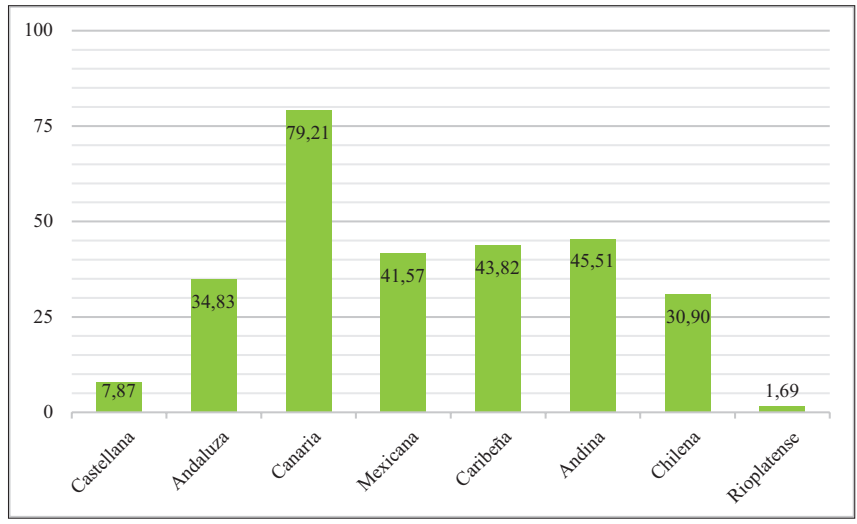

Gráfico 20. Identificación errónea de las variedades

Considerando el bajísimo grado de aciertos para estas variedades, es esperable un alto grado de errores $\mathrm{y}$, sin embargo, la variedad castellana alcanza solo el $7.87 \%$ y la andaluza, el $34.83 \%$ (porcentaje apenas superior al de la variedad chilena, la segunda mejor reconocida). No obstante, si a los porcentajes de aciertos exactos de las variedades se les agregan los porcentajes de aciertos generales (los casos que han sido identificados como pertenecientes a Hispanoamérica o España), los porcentajes cambian abruptamente: el grado de identificación de la variedad castellana asciende a $90.45 \%$ y la andaluza a $61.80 \%$.

El mismo criterio aplicado al resto de las variedades no altera la escala antes establecida para los aciertos exactos, como se vuelca en el gráfico 21.

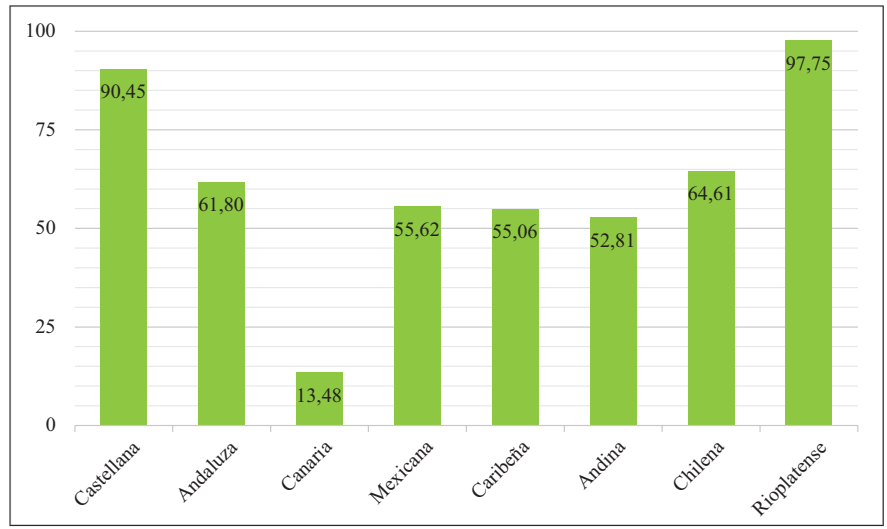

Gráfico 21. Identificación general de las variedades 
Esto apoya, al menos desde una perspectiva rioplatense, la visión de una variedad española peninsular.

\subsubsection{Valoración del resto de las variedades}

\subsubsection{Valoración directa}

La valoración directa que se hace de las diferentes variedades del español es, en general, positiva. Sin embargo, la valoración de la variedad castellana es, comparativamente, baja: concita los valores más bajos en 14 de los 24 rasgos evaluados ( 8 de los cuales reciben valores inferiores a 3 ) y obtiene la menor valoración promedio entre las variedades. Ya se ha discutido, en apartados previos, sobre aquellos rasgos en los que esta variedad se destaca (variedad urbana y clara) y se han argüido algunas razones al respecto.

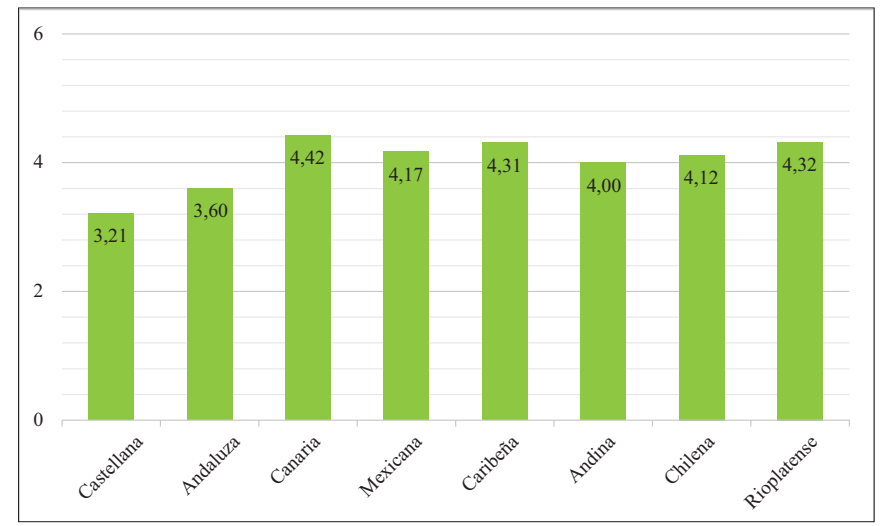

Gráfico 22. Promedio valoración directa de las variedades

La variedad caribeña, que comparte por poco el promedio con la variedad rioplatense, es la mejor percibida en 9 de los 24 atributos estudiados, solo uno menos que la rioplatense.

Las respuestas directas respecto de qué aspectos de la pronunciación de la variedad castellana los informantes valoran positiva y negativamente son poco numerosas, pero se mencionan los rasgos suave, lento, agradable y divertido, y los negativos monótono, complicado y ajeno. Lo mismo sucede con la variedad andaluza, que es valorada como cantarina, suave y divertida (rasgos positivos), pero rápida, poco espontánea y confusa (rasgos negativos).

Para las variedades hispanoamericanas, la voz mexicana gusta por su claridad y entonación, por un lado, y disgusta por su lentitud y monotonía, por el otro; a su vez, se la percibe como agradable y divertida, pero también 
como distante. La variedad caribeña agrada por la entonación en general y se la percibe como bonita y sencilla, si bien también se opina de ella que es rápida y difícil de comprender. De la variedad andina, se valora positivamente el rasgo claro, agradable y bonito y, negativamente, lo lento y monótono. Por último, la variedad chilena es valorada por el acento y la claridad, se la considera divertida, sencilla y bonita, pero también rápida y complicada.

\subsubsection{Valoración indirecta}

La valoración indirecta para todas las variedades es muy positiva. Aquí también hallamos que las variedades peninsulares son las menos valoradas. Se ha argumentado anteriormente sobre la caracterización muy positiva de la región castellana para el rasgo avanzado (región) y rico (cultura).

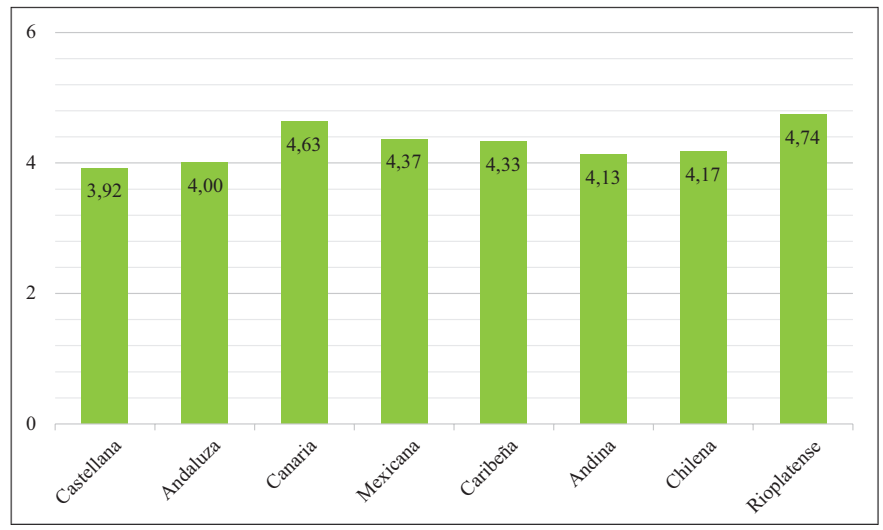

Gráfico 23. Promedio valoración indirecta de las variedades

Los rasgos mencionados para calificar a las personas de las regiones peninsulares son escasos. Algunos de ellos son seco, culto, divertido, aplicado y serio (zona castellana); y positivo, agradable y conversador (zona andaluza).

Las personas de la zona mexicana son descritas como agradables, divertidas, amables, simpáticas y sociables; los mismos adjetivos son atribuidos a la zona caribeña y andina; para la zona chilena, aparecen además los adjetivos culto y astuto. Las actitudes negativas específicas hacia los hispanoamericanos no son numerosas, salvo para las personas de la región andina (consideradas inmaduras, machistas e irritantes) y para las personas de la región chilena (antipáticas, molestas y egoístas). 


\section{CONCLUSIONES}

1. Los resultados a la fecha dan cuenta de un predominio del estereotipo del "mejor español": $52.81 \%$ a favor de la jerarquía de alguna variedad contra $32.58 \%$ a favor de la igualdad. Sin embargo, se observa una resistencia al momento de atribuir jerarquía, puesto que un $13.48 \%$ de los informantes no contesta. Se puede observar también que la preferencia por la igualdad de las variedades aumenta con la edad y el nivel de formación. Estos resultados son notablemente compatibles con los obtenidos por Llull y Pinardi (2014), quienes encuentran que, para el mismo segmento etario, el $55.3 \%$ elige alguna variedad como mejor, el $31.3 \%$ entiende que ninguna lo es y el $13.4 \%$ se resiste a responder (opción no sabe).

2. Las valoraciones directas de la variedad propia son muy positivas: 4.24 para el componente afectivo y 4.40 para el cognitivo. De este último, los rasgos menos valorados son suave y variado $(3.73 \mathrm{y}$ 3.47 , respectivamente) y los más valorados son urbano y claro (5.58 y 5.10$)$.

3. Las valoraciones indirectas de las voces rioplatenses son muy positivas en lo que refiere a la evaluación a través de la persona, de la región y de la cultura. Los rasgos simpático (persona), avanzado (región) e innovador (cultura) son los únicos valorados por debajo de $4(3.92,3.90$ y 3.99 , respectivamente).

4. El $97.75 \%$ de los encuestados identifica correctamente la variedad rioplatense y el $94.25 \%$ se reconoce como usuarios de ella.

5. En cuanto a la diversidad dialectal, los informantes demuestran ser bastante conscientes, con una menor precisión al momento de identificar variedades europeas.

6. Se manifiestan actitudes positivas hacia todas las variedades normativas del español, con menor prominencia de la variedad castellana. Con respecto a esta última, nuestros números indican que solo el $10.12 \%$ de los encuestados elige alguna variedad hispánica como modelo de "bien hablar", a diferencia del trabajo de Llull y Pinardi (2014), que obtiene un $23.1 \%$ para el mismo rango etario.

7. Si bien la variedad propia obtiene la puntuación más alta en el promedio general, no se comporta de manera homogénea en todos los aspectos de la evaluación: la variedad propia es la mejor percibida en 
10 de los 24 atributos evaluados, mientras que la variedad caribeña lo es en 9 de los 24 atributos.

8. La variedad castellana obtiene la menor valoración en 14 de los 24 rasgos analizados, de los cuales 8 se encuentran en el polo negativo. Ocupa, así, la posición más baja en la escala, aunque se destaca en los rasgos avanzado para región y rico para cultura.

9. Se podría tratar de establecer una cronología entre los resultados favorables obtenidos por las variedades peninsulares en Solé (1992), Llull y Pinardi (2014) y nuestros resultados: el $42 \%$ de los entrevistados en 1992 opinan que se habla mejor en España, el 30\% en 2014 y el $10.12 \%$ entre 2014 y 2017.

\section{REFERENCIAS BIBLIOGRÁFICAS}

Acuña, Leonor y José Luis Moure. 1999. Los hablantes de Buenos Aires opinan sobre su lengua. En Mabel Brizuela, Cristina Estofán, Gladys Gatti y Silvina Perrero (coords.). El Hispanismo al final del milenio. V Congreso de Hispanistas, pp. 1513-1523. Asociación Argentina de Hispanistas. Córdoba, Argentina: Comunicarte.

Arévalo, JaVIer Marcos. 2004. La tradición, el patrimonio y la identidad. Revista de estudios extremeños 60, 3: 925-956 [en línea]. Disponible en http://www.dip-badajoz.es/cultura/ ceex/index.php?cont=reex [Última consulta enero de 2018].

Borello, Rodolfo. 1964. Actitud del argentino medio frente a su lengua. Presente y futuro de la lengua española: Actas de la Asamblea de Filología del I Congreso de instituciones hispánicas 1: 193-198. Madrid: OFINES.

Cestero, Ana María y Florentino Paredes. 2015a. Creencias y actitudes hacia las variedades normativas del español actual: primeros resultados del Proyecto PRECAVES-XXI. Spanish in Context 12/2: 255-279.

2015b. Creencias y actitudes hacia las variedades del español en el siglo XXI: avance de un proyecto de investigación. En Dermeval da Hora, Juliene Lopes R. Pedrosa, Rubens M. Lucena (eds.). ALFAL 50 anos: contribuições para os estudos linguísticos e filológicos, pp. 652-683. João Pessoa: Ideia.

2018. Creencias y actitudes hacia las variedades cultas del español actual: el proyecto PRECAVES XXI. Boletín de Filología (este volumen).

Gili Gaya, Samuel. 1955. Curso superior de sintaxis española. Barcelona: Spes.

Llull, Gabriela y Carolina Pinardi. 2014. Actitudes lingüísticas en la Argentina. El español en Buenos Aires: Una aproximación a las representaciones de sus hablantes. En Ana Beatriz Chiquito y Miguel Ángel Quesada Pacheco (eds.). Actitudes lingüisticas de los hispanohablantes hacia el idioma español y sus variantes, Bergen Language and Linguistic Studies (BeLLS), 5: 1-62 [en línea]. Disponible en http://dx.doi.org/10.15845/ bells.v5i0.676

López García, María. 2013. El otro yo: la identidad lingüística argentina como conflicto. Amerika 9 [en línea]. Disponible en http://journals.openedition.org/amerika/4387 [Última consulta enero de 2018]. 
Marre, Diana. 2003. Mujeres Argentinas. Las chinas. Representación, género, territorio y nación. Barcelona: Universidad de Barcelona.

Paredes, Florentino y Ana María Cestero. 2018. Percepciones de las variedades cultas del español por parte de hablantes del centro-norte de España según los datos del Proyecto PRECAVES XXI: el español ejemplar y la variedad propia. Oralia 21/1: 87-112.

RAMos CALDERón, José ANTONio. 2012. Cuando se habla de diversidad ¿de qué se habla? Una respuesta desde el sistema educativo. Revista Interamericana de Educación de Adultos 34, 1: 76-96 [en línea]. Disponible en http://www.redalyc.org/articulo.oa?id=457545090006 [Última consulta enero de 2018].

Rizo, Marta. 2006. Conceptos para pensar lo urbano: el abordaje de la ciudad desde la identidad, el habitus y las representaciones sociales. Revista Bifurcaciones 6 [en línea]. Disponible en http://www.bifurcaciones.cl/006/bifurcaciones_006_Rizo.pdf [Última consulta enero de 2018].

RoJAs Mayer, Elena ET AL. 2001. La norma hispánica: prejuicios y actitudes de los argentinos en el siglo XX. En II Congreso internacional de la lengua española, Valladolid [en línea]. Disponible en http://cvc.cervantes.es/obref/congresos/valladolid/ponencias/ unidad_diversidad_del_espanol/1_la_norma_hispanica/rojas_e.htm [Última consulta enero de 2018].

SemÁn, ERnesto. 2011. La amenaza democrática. Revista Panamá [en línea]. Disponible en http://panamarevista.com/ [Última consulta abril de 2018].

Solé, Carlos Alberto. 1992. Actitudes lingüísticas del bonaerense culto. Scripta Philologica. In honorem Juan M. Lope Blanch 2: 773-822. México: U.N.A.M. 